\title{
Heads You Win, Tails I Lose: The Paradox of Canada's Lack of Support for First Nations' Traditional Healers
}

\author{
Michael Hankard ${ }^{*}$, John Charlton \\ Department of Indigenous Studies, University of Sudbury, Canada
}

Copyright $\bigcirc 2017$ by authors, all rights reserved. Authors agree that this article remains permanently open access under the terms of the Creative Commons Attribution License 4.0 International License

\begin{abstract}
Historical First Nations - Canadian relations are marked by a range of contradictions - places where opposition, inconsistency and tension dictate how the state regulates First Nations everyday life. Lack of support for traditional healers is one paradox in this relationship. Tacit denial of recognition and support for traditional healing in Canada constitutes a hidden paradox not evident to those on the sidelines of this daily life. Even though practiced for thousands of years before European contact, First Nations traditional healing practices have yet to gain full support from the government of Canada. There is a contradiction between Canada's support for international initiatives such as the World Health Organization's (WHO) Social Determinants of Health model and its lack of support for traditional healers within First Nations at home. This article explores this paradox and critiques it from an Indigenous knowledge (IK) perspective through an articulation of the holistic First Nations worldview.
\end{abstract}

Keywords Indigenous Peoples, Social Determinants of Health, Paradox

People who are unwell are unable to make decisions about the environment, governance, health and welfare or everyday living. (Elder Michael Thrasher, 2016) ${ }^{1}$

"You can't think and hit at the same time." [1]

\section{Introduction}

While one may expect support for traditional medicine, healers and Elders in light of Canada's support for the World Health Organization's (WHO) Social Determinants of Health model, this is often not the case. Unfortunately, this should not come as much of a surprise considering
Canada's history of relations with First Nations. Canada was one of the four nations opposing and among the last United Nations member nations to sign the Declaration on the Rights of Indigenous Peoples in 2008, and maintained its oppressive Indian residential school system until the 1990s. Then there is the fact that former Prime Minister Stephen Harper asserted to the developed world, while attending the September 2009 G20 Summit in Pittsburgh, PA that, "we [in Canada] also have no history of colonialism..." [2]. What is so difficult about accepting this utterance is that, the very same Prime Minister, just over a year previously, in June of 2008, formally apologized on behalf of the Government of Canada for the Indian Residential School system [3]. Worrisome is that Canada still maintains colonial rule over First Nations through antiquated laws such as the Indian Act and paternalistic control systems that regulate almost every aspect of First Nations everyday life.

Canadian-First Nations relations have been described as rife with contradictions between the state and Indigenous people [4]. Even institutions such as the academy, which ostensibly exist for and in support of the promotion of knowledge and its acquisition, often operate as extensions of the Canadian colonizing apparatus. In this way, they are active participants in furthering state assimilation goals and the colonization of Indigenous people. Other institutions also having specific political and social agendas through which operating budgets, and the overall neoliberal agenda dominate its worldview also distort, subsume and interpret IK systems to its own end.

The inability of institutions to embrace, and instead to foster assimilation, subversion and interpretation of IK is an ongoing threat to traditional healing as a knowledge system for Indigenous people. Within the social determinants of health model are colonial interpretations that underlie the paradox between Indigenous people and the Canadian state. 


\section{The Social Determinants of Health}

Canada's health care system has historically been predicated upon the bio-medical, cure the individual's disease through treatment, and approach [5]. Relatively recently, Canada has embraced the population health approach (PHA) that seeks to improve individual health by measuring and improving the health of the population within which we all live [6]. What is measured within the PHA approach is known as social determinants of health. The WHO defines the social determinants of health as:

"...the conditions in which people are born, grow, live, work and age. These circumstances are shaped by the distribution of money, power and resources at global, national and local levels. The social determinants of health are mostly responsible for health inequities - the unfair and avoidable differences in health status seen within and between countries" [7].

It is important to note that the underlying assumption of the population health approach is that in order to reduce health inequalities, reductions in both material and social inequalities must occur. According to the Public Health Agency of Canada (PHAC), the socio-economic status (SEC) of a population is equally or more important to health status than health or personal health behaviours [8].

The World Health Organization's original social determinants of health index include ten criteria: (1) the social gradient, (2) stress, (3) early life, (4) social exclusion, (5) work, (6) unemployment, (7) social support, (8) addiction, (9) food, and (10) transport [9]. Seven years later, a Canadian-specific index was developed increasing the number of social determinants of health in Canada to fourteen [10]. These criteria included: (1) Aboriginal status, (2) gender, (3) disability, (4) housing, (5) early life, (6) income and income distribution, (7) education, (8) race, (9) employment and working conditions, (10) social exclusion, (11) food insecurity, (12) social safety net, (13) health services, and (14) unemployment and job security. It was later proposed that colonialism be added as a "broader social determinant of health" for evaluating those affecting Indigenous people and creating a more Indigenized social determinants of health framework [11].

Since its inception, the number of proposed social determinants of health has climbed from its original ten to fifteen. Exploring the First Nations worldview is useful for illustrating tensions organizing the paradox, and to clarify how the population health approach remains embedded within Canada's public health policy.

\section{Seeking Balance or Balancing the Books?}

The main reason underlying the paradox of Canada's lack of support for traditional healers relates to differing worldviews. The population health approach and its tension with the First Nations worldview illustrate the most evident differences. Canada applies limited, colonial ways of understanding to its First Nations relations which greatly constrain its conceptual framework and magnify misunderstandings with and of First Nations. Canadian society is also grounded in capitalistic principles, such as managerial accounting practices that organize its colonial practices. These narrow conceptions of reality and understanding applied to complex internal societal issues lead to the continued reliance on authoritarian and both covert and overt forms of oppression that linger within Canada-First Nation issues.

Consider the First Nations worldview. It is holistic, relates to the role of Indigenous people within Creation and duty to maintain balance in all aspects of our being. It is also often referred to as Indigenous knowledge (IK). Within this way of relating and understanding, all aspects of Creation are interconnected and inseparable. Medicine circles are often used to illustrate this conceptually as several thousand Indigenous teachings are found within it as well as the overriding concept of balance. These concepts serve as the foundation of traditional teachings and the published literature relevant to Indigenous ontology [12].

This worldview is embedded within our language. Elders raised speaking the Anishinabek language from birth have shared with $\mathrm{me}^{2}$ that within it each word has 28 different meanings. For example, b'maadzowin may literally translate into "good life," but therein is the notion of balance within three areas--good health, peace of mind, and good, long life. Within those are a number of other preconditions, assumptions and meanings within Anishinabek understandings, some of these are public, but many (particularly as they pertain to ceremony) are not.

There are also countless 'teachings' that illustrate Indigenous ontology, often on a number of different levels, to clarify the need for balance. For example, consider the life journey within which one can become aware of how it proceeds starting with birth. It can be illustrated on a medicine circle that is presented orally. In this teaching, humans are given four gifts when we are born into life: (1) movement, (2) vision, (3) time, and (4) feeling [13]. Each gift develops as we progress through the process of physical birth, actual separation from the mother's womb, and movement of bodily functions, into sound and sight that develop a number of days after birth, into time which can become distinguished by a baby based on feeding, the light and dark and activities of its mother, and then into feeling, which is marked by the ability to distinguish hot and cold, kindness, gentleness and love. When an infant is born they acquire these gifts in a logical sequence and the

\footnotetext{
2 This has included Elders such as the late Emma King of Wauskasing First Nation (ON), the late Harold Ashkewe of Chippewas of Nawash Unceded First Nation (ON), and others over a period of 25 years.
} 
ability to 'move' them, develop them and bring them into being marks their readiness for higher levels of learning and discovery which begin another turn around the medicine circle.

The depth and emphasis on balance is further illustrated through the Anishinabek word for good life. I have learned that to attain b'maadzowin or 'good life,' the precondition of balance is required. This is evidenced through medicine circles which have two sides (positive and negative), but also equal proportion within all four quadrants of each circle that make reference to a common whole. Within these circles are humans, as we exist as part of, and connected to, each of the other elements of Creation-mineral, plant and animal. According to traditional oral teachings and the literature, we cannot disconnect any of these elements from each other or else lack of balance or unwellness results. When any of the parts of Creation are imbalanced, all of the other parts are affected as well. In humans, one very important way that we are able to correct our imbalance (and in so doing correct the imbalance existing within the other elements or segments of Creation) is through the use of traditional healing and medicines.

Implicit within b'maadzowin or minob'maadzowin (which also means good life) is the notion that traditional health, ceremony and interpersonal relations (including Elder counselling) are inseparable from wellness affecting the individual, family, community and nation. Each segment of the community is interconnected in the same way that each segment of Creation, for example, the mineral, plant, animal and human are intereconnected. Further connected to these are the aspects of Creation that are seen and unseen. These also constitute our interconnected universe and our daily lives.

There is also reciprocity. By offering acknowledgement and thanks in our everyday lives, such as tobacco and prayers when we pick our medicines that we use in ceremony, we strengthen our connection to and the overall balance within which we exist in Creation. Elders have told me that unwell and imbalanced people cannot function well in their lives, care for their families, their environment, or even their responsibilities in their everyday lives.

\section{The Land, Humans and Spirituality}

The paradox is also evident within Canada's lack of understanding of the First Nations connection to the land, humans and spirituality. First Nations people having balance and wellness do not perceive the environment as disconnected, non-animate elements existing within an artificially constructed silo. Instead we perceive these as intrinsic interconnected elements of Creation that we are connected to and cannot live without. In this way, spirituality is inseparable from the land. These insights, conveyed through oral tradition, are often multilayered, complex (although seemingly simple), and defy colonial boundaries. They are interpreted and applied to varying contexts and have survived colonialism through their contextual application and flexibility.

Even though it was held over twenty years ago, the 1996 Royal Commission on Aboriginal Peoples (RCAP) continues to offer insight into ontological concepts at the core of the Canadian - First Nations paradox. These include the spiritual relationship of Indigenous people to the land, natural resources and the environment. Universally, it was found that culture and spirituality formed the basis for the interface between natural resources, the environment and Indigenous peoples. Testimony before the Commission repeatedly emphasized how the land and spirituality, identity and cultural practices are interconnected.

RCAP testimony pertaining to the land notes its roots within spirituality. Testimony repeatedly emphasized this relationship, stating that "Physical, emotional, spiritual and environmental health are all essential aspects of well-being. When they are in balance, health and wellness prevail. When they are out of balance, ill health and social discord predominate." It was further described that the "Preservation of the natural habitat is a vitally important factor in the agricultural, cultural and spiritual practices of Indian bands." Further, that "Aboriginal people from almost every culture believe that health is a matter of balance and harmony within the self and with others, sustained and ordered by spiritual law and the bounty of Mother Earth. They have long understood that the well-being of people depends on the well-being of the air, water, land and other life forms" [14].

Balance is foundational within these beliefs. Without balance, nothing in Creation can exist. When there is imbalance, whether within any of the Earth's elements, the Earth itself, the planets in its universe, or anything or anyone living on it, or remotely connected to it, Creation always finds a way to correct it. This is not just a First Nations way of connecting dots, but rather a way of understanding that Natural laws apply not only to humans, but to all of Creation.

The RCAP also highlighted the role of equality. RCAP testimony describes how "In traditional Aboriginal cosmologies, all life forms are seen as aspects of a single reality in which none is superior. The elements of nature- from the muskrat to maple to mountain - are like parts of the self. Thus, loss of land and damage to lands, waterways and so on are experienced as assaults on one's own body and on the personal and collective spirit" [15]. It importantly notes:

The fundamental nature of Aboriginal worldview was, and continues to be, that all of life is a manifestation of spiritual reality. We come from spirit; we live and move surrounded by spirit; and when we leave this life we return to the spirit world. All perceptions are conditioned by spiritual forces, and all actions have 
repercussions in a spiritual reality. Actions initiated in a spiritual realm affect physical reality; conversely, human actions set off consequences in a spiritual realm. These consequences in turn become manifest in the physical realm. All these interactions must be taken into account as surely as considerations of what to eat of how to keep warm in the winter [16].

The relationship between humans and the land is critical. In testimony before the Royal Commission, Will Basque of Eskasoni, Nova Scotia stated that "When Aboriginal people speak of the land they mean not only the ground that supports their feet; they also include waters, plants, animals, fish, birds, air, seasons - all the beings, elements and processes encompassed by the term 'biosphere."' [17]. The Commission stated that "This theme of renewal of life, accomplished through prayer and proper behavior, is repeated in the oral traditions of all Aboriginal nations. It is often referred to as "maintaining a balance." [18]. In addition, Elder Alex Skead asserted that "The songs of the prophet Nógha convey this idea of harmony in the relationship between the earth and all those who inhabit the lands and the waters" [19].

The all encompassing interconnection of Creation is also clear. This is echoed in the statement that "Our responsibilities to Mother Earth are the foundation of our spirituality, culture and traditions" [20]. Further, it was stated that "The way people have related to and lived on the land (and in many cases continue to) also forms the basis of society, nationhood, governance and community. Land touches every aspect of life: Conceptual and spiritual views; securing food, shelter and clothing; cycles of economic activities including the division of labour; forms of social organization such as recreational and ceremonial events; and systems of governance and management [21]. Another person testifying at the Commission stated that "Traditional Aboriginal government, culture, spirituality and history are tied to the land and the sea. Our history is passed onto the present and future generations through old traditions in such forms as songs, dances, legends, ceremonies and kinship relations. Our grandparents believe our old traditions top and strengthen the laws and practices necessary to uphold harmony between people and the world we live in" [22]. It was also asserted that "Spiritual beliefs, ceremonial activities, and practices of sharing and mutual aid also helped to define appropriate and necessary modes of behavior in harvesting and utilizing resources" [23]. It was also said that "Aboriginal languages did not have such a term, and many Aboriginal people today do not feel comfortable applying that term to their own ways of doing things" [23].

Finally, differences in ontology are reflected by the lack of certain words commonly used in the English language. This creates gaps in understanding and relating that contribute to the paradox. It is worth reiterating that the closest term conveying a related meaning is b'maadazowin or good life because it implies the existence of balance and wellness within all of Creation. In the Abenaki language (Western dialect), we make reference to the Earth as N'Gwas N'Dakinna. In a literal translation, this means "our Mother, the Earth." However, knowing there the actual understanding of Indigenous phraseology often differs from the words used to describe a concept, from a traditional perspective, this term not only describes the Earth where we live, but also how all life on it is dependent upon her and how all segments of Creation inter-relate, coexist and depend on her and each other. Since everything upon the Earth is, from an Indigenous standpoint, a natural resource or part of the natural world, it is therefore logical to conclude that this interconnection is sacred and linked to spirituality and the continuation of balance.

\section{Conclusions}

Since the time of Creation the population of the Onkwehonweh were instructed. That's why we always go back to the time of Creation. We were always instructed from that time: Where did we come from? And what's our purpose in being here? [24]

The instructions referred to by the late Chief Jacob Thomas are the original instructions that Indigenous peoples were given by the Creator. These are followed through Natural laws that place us within, instead of superior to, everything in Creation. Perceiving life and our place within that cycle shapes how we have existed throughout the millennia. The 'purpose in being here' question he asks makes us return to those instructions because they have withstood the test of time. Our continued existence and ability to survive is often tested, in today's case, through the forms expressed through colonialism.

Colonialism supports the Canada - First Nations paradox and its lack of support for First Nations. It fosters the assimilation goal of forcing cultural practices and beliefs into non-Indigenous frameworks through institutional oppression. We face this daily as First Nations people, intentionally and unintentionally, through ignorance or lack of awareness, and in furtherance of the colonization project. Exploring the continued and often expanding, institutional oppression of First Nations through colonial interpretations of IK contravening what we know to be true as Indigenous people remains critical.

Creating and enforcing narrow, colonial borders expands and perpetrates the Canadian colonization project. While this article sought to explore the underlying reasons for the population health approach paradox, it also hopes to encourage exploration into how institutions foster and participate in colonizing behaviours. By exploring the underlying reasons for suppressing traditional IK and worldview, it sheds light on some of the possible motives for removing the 'Indigenous' from 'knowledge' in IK and how that oppresses Indigenous people through the shaping of narrowly defined ways of thought and belief excluding 
traditional healing from the agenda. It also raises issues concerning possible outcomes of this form of colonization and its potential impact on the next seven generations of First Nations.

It is worthwhile elaborating on Elder Michael Thrasher's opening statement on the connection between unwellness and poor decision making skills. In stating that "People who are unwell are unable to make decisions about the environment, governance, health and welfare or everyday living," he is referring to the inability of those lacking something to share it with others. Consider this light of the WHO's assertion that the "...distribution of money, power and resources..." shapes the social determinants of health. This contrasts with a fundamental precept of Natural law and IK that you cannot give away what you do not own.

How can those lacking balance make decisions? Traditional teachings assert that with balance comes creativity. When balance is suppressed or removed, what remains are mechanical, rote elements of bureaucratic decision making processes that not only lack spiritual creativity and balance, but also apply assembly line problem solving skills far removed from IK and ecological systems. To begin with, they no longer function properly. This is what colonial worldview does to IK as a form of knowledge. It brings imbalance, stressing and prioritizing only that which furthers a particular political, economic or social agenda, while ignoring important aspects critical to preserving IK systems.

For Canada to grow as a democratic society, it must draw from and adopt First Nations ontology, and in doing so, embrace and recognize the value of the culture on which Canadian society is built. To do this requires honouring the connection between the individual and Creation. This includes prioritizing individual wellness and that of families, communities and nations. When there is a lack of balance within these relationships, the other aspects are also affected. This produces imbalance and dysfunction within the circle. This is at the heart of the paradox.

\section{REFERENCES}

[1] Berra, Yogi. The Yogi Book: I Really Didn't Say Everything I Said! New York: Workman Publishing, 1999.

[2] D. Ljunggren. "Every G20 nation wants to be Canada, insists PM," Reuters.com, September 25, 2009.

[3] Indigenous and Northern Affairs - Canada. Statement of apology to former students of Indian Residential Schools. Stephen Harper, Prime Minister of Canada, June 11, 2008.

[4] Wotherspoon, T. And Hansen, J. "The "Idle No More" Movement: Paradoxes of First Nations Inclusion in the Canadian Context," Social Inclusion. Vol. 1, p. 21-36, 2013; and Fiske, Jo-Anne and Browne, Annette. Paradoxes and Contradictions in Health Policy Reform: Implications for First Nations Women. British Columbia Centre for
Excellence for Women's Health. Vancouver, BC. 2008.

[5] Raphael, D. Social determinants of health: Canadian perspectives. Toronto: Canadian Scholar's Press, 2004.

[6] Douglas, V. Introduction to Aboriginal health and health care in Canada: Bridging health and healing. New York: Springer, 2013.

[7] WHO. Social determinants of health. Retrieved from http://www.who.int/social_determinants/sdh_definition/en/ $(\mathrm{n} / \mathrm{d})$.

[8] Public Health Agency of Canada. Income inequality as a determinant of health, 2002. Retrieved from http:/www.phac-aspc.gc.ca/ph-sp/phdd/pdf/overview_impli cations/02_income_e.pdf

[9] Wilkinson, R. and Marmot, M. The Solid Facts. Copenhagen: World Health Organization, 2003.

[10] Mikkonen, J. and Raphael, D. (2010). Social Determinants of Health: The Canadian Facts. Toronto, Canada: York University School of Health Policy and Management.

[11] Czyzewski, Karina. "Colonialism as a Broader Social Determinant of Health." The International Indigenous Policy Journal, (2) (1), May 2011.

[12] Benton-Banai, Edward. The Mishomis Book: The Voice of the Ojibway. Hayward, WI: Indian Country Communications, July 1988; Bopp, Julie. The Sacred Tree: Reflections on Native American Spirituality. Four Worlds Development Project. Wisconsin: Lotus Press, 1988; Cajete, Gregory. Look to the Mountain: An Ecology of Indigenous Education. Asheville, NC: Kikaki Press, 1994; Johnston, Basil. Ojibway Ceremonies. Toronto: McClelland \& Stewart, Inc., 1982; Nabigon, Herb. The Hollow Tree: Fighting Addiction with Traditional Native Healing. Montreal and Kingston: McGill-Queens University Press, August 2006; Ross, AC. Mitakuye Oyasin: We are all related. Ft. Yates, ND: BEAR, March 1989; Ross, Rupert. Indigenous Healing: Exploring Traditional Paths. Toronto: Penguin Canada Books, 2014; Simpson, L. Dancing On Our Turtle's Back: Stories of Nishnaabeg Re-Creation, Resurgence and a New Emergence. Winnipeg: Arbeiter Ring Publishing, 2011; Wilson, Shawn. Research is Ceremony: Indigenous Research Methods. Halifax \& Winnipeg: Fernwood Publishing, 2008.

[13] Thrasher, Michael. Traditional First Nations Teachings: 2001-2017.

[14] Canada. Royal Commission on Aboriginal Peoples. Report. Volume 3, Gathering Strength, Health and Healing. Ottawa: Minister of Supply and Services Canada, 1996, p. 150-178.

[15] Canada. Royal Commission on Aboriginal Peoples. Report. Volume 3, Gathering Strength, Health and Healing. Ottawa: Minister of Supply and Services Canada, 1996, p. 171.

[16] Canada. Royal Commission on Aboriginal Peoples. Report. Volume 1, Looking Forward, Looking Back. Ottawa: Minister of Supply and Services Canada, 1996, p. 600.

[17] Canada. Royal Commission on Aboriginal Peoples. Report. Volume 1, Looking Forward, Looking Back. Ottawa: Minister of Supply and Services Canada, 1996, p. 603.

[18] Canada. Royal Commission on Aboriginal Peoples. Report. Volume 1, Looking Forward, Looking Back. Ottawa: 
Minister of Supply and Services Canada, 1996, p. 604.

[19] Canada. Royal Commission on Aboriginal Peoples. Report. Volume 2, Restructuring the Relationship. Ottawa: Minister of Supply and Services Canada, 1996, p. 427.

[20] Canada. Royal Commission on Aboriginal Peoples. Report. Volume 2, Restructuring the Relationship. Ottawa: Minister of Supply and Services Canada, 1996, p. 428.

[21] Canada. Royal Commission on Aboriginal Peoples. Report. Volume 2, Restructuring the Relationship. Ottawa: Minister of Supply and Services Canada, 1996, p. 439.

[22] Canada. Royal Commission on Aboriginal Peoples. Report. Volume 2, Restructuring the Relationship. Ottawa: Minister of Supply and Services Canada, 1996, p. 441.

[23] Canada. Royal Commission on Aboriginal Peoples. Report. Volume 2, Restructuring the Relationship. Ottawa: Minister of Supply and Services Canada, 1996, p. 449.

[24] Canada. Royal Commission on Aboriginal Peoples. Report. Volume 1, Looking Forward, Looking Back. Ottawa: Minister of Supply and Services Canada, 1996, p. 602. 